\title{
Take this Work Global
}

\author{
Ian Cornelius
}

\begin{abstract}
Paul Eggert's The Work and the Reader in Literary Studies: Scholarly Editing and Book History elaborates a general program for the study of literature centered on the question, "What is the thing read?" Concepts of document, text, and work are parsed with care, generating many valuable insights and clarifications, but there is need for more thinking about the linguistic medium of literature. To textual studies, bibliography, and book history - the trio of foundational disciplines advocated by Eggert — one should add philology, or the study of literary language.
\end{abstract}

F

Irst off, I register the great ambition of Paul Eggert's new book. The Work and the Reader in Literary Studies: Scholarly Editing and Book History (2019) proposes a general model for the study of literature. This ambition is evident especially in Eggert's pointed engagements with Rita Felski's The Limits of Critique and Caroline Levine's Forms: Whole, Rhythms, Hierarchy, Network, books that, Eggert argues, fail to answer the "central question for literary study": "What is the thing read?" (2019, 17, 110 , emphasis in original). The question has a philosophical form to which Eggert is attuned, yet he contends that flights to ontology and sociology are unhelpful, for they miss the specificity of the object or take it for granted. Normal "literary-critical activity" fares little better, for it "typically leaves unaddressed, as somehow beneath notice, the question of exactly what it is that is read, what it is that is interpreted" (EGGERT 2019, 10). The proper tools are to be found in textual criticism, bibliography, and book history, empirical disciplines to which literary studies owes its basic supply of reading matter. Textual criticism, bibliography, and book history are disciplines purpose-built to answer the question "What is the thing read?", even if, or perhaps just because, these disciplines cannot get by on empiricism alone. Far from trading in raw facticity, the disciplines of text and document cannot, Eggert contends, organize their materials into usable form without recourse to a concept of an agented literary "work". 
As in his Securing the Past: Conservation in Art, Architecture and Literature (2009), Eggert maintains that literary reading is always double. At one level, we read texts borne by documents (often, printed books) or displayed to a digital terminal (or "interface"). This might be termed the etic dimension of reading — reading as it may be perceived by a literal-minded external observer - and it implies, as its complement, an emic dimension. Readers of literature routinely speak of reading agented works (Shakespeare's Hamlet, for instance), and Eggert argues that this ordinary way of speaking should be treated with respect by the technical disciplines, which deceive themselves in claiming to do without concepts of agency and the work. Rather than chase these concepts from the room, the technical disciplines should make them tractable, elaborate their implicit content, and locate the grounds and limits of their authority.

In case studies and theoretical argument, Eggert advocates for a dynamic concept of the work, as the emergent product of open-ended, multiply agented, text-based semiosis. Because semiosis unfolds in time, works acquire internal differentiation, placed under control by speaking of "versions" of the work. Because there is no extra-semiotic ground from which to designate a work or work-version, such designations are inherently interpretative, imbricated in history, and obligated to take the form of an argument. In Kantian terms appropriated by Eggert, the work and version are "regulative" principles, not constitutive: they may guide inquiry but do not legislate to it, and they remain open to challenge and retraction $(2019,33-4,173)$. There is no such thing as a "definitive edition", only more or less persuasive presentations of the text of a work or work-version. Any new edition of a work becomes part of the "life of the work"; a good scholarly edition makes the life of the work newly accessible to readers (EGGERT 2019, 93-4).

In Eggert's reasoning, there is a fundamental distinction between questions of the form "What are the readings of manuscript Peniarth 392D (Hengwrt 154) in the National Library of Wales?" and "What are the readings of the Canterbury Tales?" The first question concerns a literary document, the second a literary work. Textual enterprises limited to questions of the first type are designated by Eggert as "archival" and distinguished by him from scholarly editing as such. An edition, he writes, properly "enacts [. . . ] a theory or a proposition about how the work exists and has existed in the world" $(2019,6)$. The text of a literary document becomes evidence for the text of a literary work only in aggregate - that is, when arrayed within the whole documentary record of the work in question - and when subjected to critical judgment. I will have more to say below about this distinc- 
tion between archive and edition. Left unbated, the distinction would slice the title "edition" from many publications that lay claim to that status. Eggert bates the foils by evoking a "sliding scale" and acknowledging that any presentation of literary text must compromise between archival and editorial "impulses" $(2019,86)$. He refuses, however, to compromise on the basic contention that, in producing a clean reading text wrapped in annotation, an editor presents a literary work and ought to own up to that. Chapter III, "The Digital Native Encounters the Printed Scholarly Edition Called Hamlet", argues vigorously against the ascendancy of conservative, singletext editions of Shakespeare's works. "Best-text editions" of the Canterbury Tales are vulnerable to similar criticism, as urged long ago by E.T. Donaldson and subsequently by Ralph Hanna, among others (DonALDson 1972; Hanna 1987, 1996, 130-39). Basically, the contention is that a "best-text edition" expresses an incoherent combination of allegiances. Either an editor should present the text of the document, recommending that text to readers for reasons other than its ability to represent the work (does the document, for example, illustrate the efforts of a well-connected scribe to source exemplars in response to an avant-garde of patronal demand?), or the editor should engage the work at the level of its fundamental, inherent unit of variance - the lection - and argue, lection-by-lection, for the authority of the text presented. In the second case the editor's argument would be based in evaluation of the whole relevant textual record and systematic analysis of the language of the work.

The readings of a literary document may be contestable for many reasons. Graphic forms may be irregular and ambiguous in execution, complexly abbreviated or overwritten, effaced or otherwise damaged, or executed in a script not well represented by Unicode character sets. Yet an edition of a work is contestable at a deeper ontological level, for a literary work - as distinct from a document - is not demonstrable. An edition is therefore obliged to become "a form of argument" (EGGERT 201964 and 191 n1). I am reminded of Ralph Hanna's pedagogical efforts to impress upon students of Middle English literature a basic apprehension that editing is "an interpretative act, not especially different from the critical act" (HANnA 1996, 64, cf. 1988, 2000). Interpretation and judgment may be subjected to training: the "examination of variants" is the topic of the longest chapter in Hanna's recent handbook (2015). Yet, for both Eggert and Hanna, the logical canons of textual criticism are made to accommodate considerations of a more rhetorical character. Hanna, though a disciple of George Kane's method of direct editing, has never imitated the austere presentational regime of the Athlone Piers Plowman, a regime that, as 
Eggert remarks, "ignores the role of a readership in the transaction" (2019, $191 \mathrm{n1})$. Eggert observes cunningly that, "If the edition is to be seen as an argument then it is necessarily one that is addressed to an audience" (2019, 82 , emphasis in original). He places editors under obligation to shape their products to the needs of readers, including through fuller annotation, and he points out that digital media facilitate this editorial charge by releasing editors from limitations inherent to print publication.

The affordances of digital media for textual editing are a central theme of this book, developed most fully in chapter V, "Digital Editions: The Archival Impulse and the Editorial Impulse". Media theorists teach us to expect that the conceptual affordances of a new medium (the idea of print, for example, or of the internet) may be as consequential as technical innovation itself. Eggert pursues this line of thinking, contending that digital media not only facilitate the editorial charge - through hyperlinking and reduced publication and storage costs, for example — but also clarify what editing always was, or should be. In 1993, near the beginning of the digital revolution in regimes of publication of scholarly editions, Hoyt N. Duggan, ventured that, "To a considerable degree, the structured antagonism between conservatives and interventionists is not inherent to editorial practice or principle. Rather, it is economically constructed by the intrinsic limitations of print technology" (DugGan 1993, 57; see EgGert 2019, 196 n2). Electronic media, Duggan reasoned, would release editors from an obligation to choose between diplomatic-conservative and critical-interventionist alternatives: hyperlinks and style sheets would permit digital editions to honor both archival documents and the literary works imperfectly transmitted in them. Twenty-five years on, Eggert urges that differences of principle are indeed at stake, and that digital media have helped to bring the differences to consciousness. Much as Duggan foresaw, digital media have facilitated the production of "special-purpose collection[s] of digital surrogates of original text-bearing materials that centre on a particular subject, author, work or group of works" (EGGERT 2019, 80). These special-purpose collections have come to be termed "archives", a usage that Eggert embraces because it permits the designation "edition" to be reserved for critical presentations of the text of literary works. Whether served out in paper books or on-line, an edition aims to present (the text of) a literary work. Publication of the text of a document is a different kind of enterprise, and deserves a different name. In Eggert's argument the English verb edit reaches a new apogee of semantic specificity and differentiation from its basic etymological sense 'to publish'. 
Though rooted in the study of nineteenth- and twentieth-century literature in English, central tenets of Eggert's thought are generalizable across the medieval/modern divide, as I have intimated in previous paragraphs. This generalizability is significant because scholars have long recognized a historical fault line. The existence of authors' drafts (as often for modern literature) and the evidentiary importance of unplanned, semi-professional, or miscellaneous allographs (as often for late medieval literature) are qualities of the textual record rightly seen to require differentiated and specialized forms of attention (HANNA 1996, 7-9; GABLER 1994; cf. TANSELlE 1983). Eggert's call for editions to enact "a theory or a proposition about how the work exists and has existed in the world" (EGGERT 6, quoted above) engages our discipline at a base-level, prior to the methodological differentiations necessitated by the peculiarities of our respective historical archives (here reverting to the traditional sense of that word). Eggert's argument for the central importance of bibliography and book history also translates well. Case studies of the publication history of Rolf Boldrewood's Robbery under Arms (1882 et seq.) and the compositional process of Joseph Conrad's Under Western Eyes (1907-1910) are among the most absorbing and memorable pages in Eggert's book. It would be interesting to pair these studies with, for example, an account of the production of the Hengwrt manuscript of the Canterbury Tales (Hanna 1996, 140-55, continued in 2013, 153-65) or an essay in materialist-historicist stemmatics (HANNA 1996, 66-73, 83-93; 2013, 110-31). The common target of these studies is the presumption that the literary work exists anywhere in an ideal, unitary, or self-identical state. This presumption is challenged as forcefully by upstream texts such as Conrad's working drafts as by downstream texts such as scribal copies of the Canterbury Tales. Once freed from service to editorial ends, stemmatics becomes a tool for cultural history: each new presentation of a work raises anew the question of its meaning.

In Securing the Past and in chapter II of the present book, Eggert extends the impulse of theoretical generalization beyond literary studies. He advances a trans-medial theory of the work of art and analogizes the editing of literary texts to conservation and restoration of paintings and historic buildings. These are stimulating lines of inquiry. I am tempted to extend the game by offering for consideration the case of Polykleitos of Argos (fl. c. 460-410 все), credited with establishing the high classical style in Greek sculpture. Polykleitos is celebrated especially for the Doryphoros ("Spearbearer"), a work "whose impact on Western art is quite incalculable" (Stewart 1990, 160). Yet no object shaped by Polykleitos's 
hand survives. The original hollow-cast bronzes are lost. The surviving archive consists of Roman copies executed in marble, some fragmentary plaster molds, ancient literary testimonia, and four or five brief excerpts from and summaries of a treatise written by Polykleitos on his art. In museums and classrooms the Roman copies may serve as surrogates for the lost originals. In professional scholarship the problem spawned a subdiscipline termed Kopienkritik: Roman marbles deemed to be copies of lost Greek bronzes were assembled into "replica series", then evaluated and compared in minute detail, aiming to project, from the series of replicas, the veining, musculature, hair swirl, and other formal features of the lost original (HALLETT 1995; MaRvin 1997). The particular tastes and agendas of Roman sculptors and their patrons must be taken into account and may become the primary object of study. There is a certain resemblance between Kopienkritik and editorial and text-critical enterprises that aim to reconstruct an authoritative text of a literary work, on the basis of allograph copies that are belated, displaced from the originating cultural environment, and imperfect. In fact, the resemblance is no accident: Miranda Marvin shows that Kopienkritik was developed by students of Karl Lachmann on analogy to textual stemmatics (Marvin 2008, 142-44).

To perceive an affiliation between Lachmannian textual stemmatics and art-historical Kopienkritik brings one up against the kind of trans-disciplinary discursive logics analyzed by Michel Foucault in The Order of Things. Eggert's recent books show the extent to which the historical humanities have renovated their own foundations, opening space for a concept of "the work" that does not presume the purity of an origin. This is a significant achievement, yet it also shows that Eggert's theory of the work unfolds at a high level of abstraction, where it may be vulnerable to the same criticism Eggert himself lodges against Felski and Levine. Does Eggert's theory of the work grasp the specificity of the thing read? The question orients the remainder of this essay.

In a long review of Securing the Past, Hans Walter Gabler argues that Eggert's editorial theory and his theory of the literary work do not reckon adequately with the linguistic medium of literature, that is, with literature as art made from language (GABLER 2010). In Gabler's assessment, there is a basic, unbridgeable difference between works of art in language and works of art in any other medium:

[T] he work of art in language is brought about by harnessing — by yoking together - elements (words, phrases, structures of grammar and syntax) that always already have cores of meaning. The work in language is consequently at bottom predicated on a pre-existing semantic core and 
potential for communication in its material substratum and is thus, in essence, not so much representative as communicative.

The inherently communicative nature of language means that a work of art in language always projects, from its linguistic material, an originator of the work and a recipient. The originator and recipient - call them author and reader - are functions of the linguistic medium. Gabler credits this apprehension to Foucault's "What is an author?"; a more apt reference is to Émile Benveniste's concept of énonciation. References to Foucault in subsequent dialogue (GABLER 2012; EGGERT 2019, 171-75) are a red herring and detract from Gabler's central contention, which is that theories of editing must not ignore the linguistic medium of literature. Language, Gabler observes, is inherently iterable: "what is penned or printed in language is copyable without limit in any number of exemplars which all instantiate the work" (2010, 110). Language is also inherently variable. And language is not inherently material: in principle the work of art in language "can exist without being recorded in writing, thus without instantiation in script" (GABLER 2010, 110), nor is the work identical with any of the documents recognized as instantiations of it. "[M]ateriality must be thought of as accidental to works in language" (GABLER 2010, 111). These claims throw up obstacles to a trans-medial theory of the work of art, and to analogies between the editing of literary texts and conservation and restoration of paintings and historic buildings. The implications for Eggert's current book are, I think, of a different order, and stem from the basic fact that language is multiple. Any general program for the study of literature should confront the basic fact of linguistic multiplicity.

Eggert does not provide guidance for study of multilingual literary cultures or literature in translation. The omission is not his fault, of course. The circulation of literature between and across languages is structurally suppressed from consciousness in modern Departments of English, which thereby misrepresent literary culture as it exists and has existed over most of the world and most of literate history. There is need in Eggert's program for a more productive engagement with "world literature", a field that he dispatches via brief critical appraisals of the work of Wai Chee Dimock and Franco Moretti. Eggert's case studies - detailing the up-take by publishers in London of works authored and first published in colonial New South Wales, for example - are in fact exemplary studies in "world literature", but they do not yet supply models or concepts for thinking about literature that crosses languages. Medievalists have much to offer in this area see, for instance, essays collected under the rubric "Language Barriers" in 
HANnA (2017) - but Eggert's program, as set out in this book, demands a more theoretical conceptualization than yet offered by the scholarship in my field. I find a promising theoretical model in Alexander Beecroft's recent proposal for an "ecology of world literature" (2015).

Beecroft is a comparatist who began his career studying the authorship, compilation and circulation of lyric poetry in ancient Greece and early China. His An Ecology of World Literature: From Antiquity to the Present Day (2015) articulates a structured array of concepts for large-scale literary study. For Beecroft, the metaphor of ecology emphasizes the great diversity of historical dispensations of literature worldwide, and the formative relations between literary cultures and their dynamic environments. The central questions of literary ecology, Beecroft suggests, are "how literature circulates, [and] what sorts of constraints operate on that circulation" $(2015,25)$. His approach is basically typological. He articulates six "ecologies' of literature, ordered into three pairs: epichoric and panchoric; vernacular and cosmopolitan; national and global. Briefly, epichoric literature is limited in circulation to the communities and places referenced in it (think of a praise poem not yet transported from its referential occasion), whereas panchoric literature circulates between several generative communities (think of collections of troubadour lyric, or the transmission of skaldic verse within prose narrative and treatise). Vernacular literature circulates in a subordinate place-bound language and under the influence of a cosmopolitan counterpart, whereas a cosmopolitan literature circulates in elevated sociolinguistic domains over large geographical regions and across multiple polities and ethnic groups (medieval English and medieval Latin form such a pair). National literature is the dispensation that modern Departments of English struggle to disengage themselves from, whereas global literature is notionally borderless. Beecroft's theorization remains at an early stage of elaboration. For us, the key point is that the six literary 'ecologies' are differentiated by mode of circulation. Beecroft conceives of circulation principally in terms of linguistic encoding and - in the case of the epichoric-panchoric pair - the use or not of writing. Textual transmission and the material form of text-bearing documents are obviously relevant, as Beecroft recognizes (Beecroft 2015, 123-34). He and Eggert bring complementary sets of tools and questions to literary study.

For a project that operates at the confluence of textualism and comparatism, one may consider the Bibliotheca Polyglotta, an ambitious online library, reading interface, and search application in development by a research team at the University of Oslo. The project describes itself as "a multilingual corpus of historically important texts", aiming to facilitate study of the historical diffusion of concepts across languages (BRAARVIG 
and Nes $\varnothing \mathrm{EN}$ 2007-2015). Among the many works now available for synoptic multilingual reading are the Bible, the Qur'an, and Buddhist scriptures, Boethius's Consolation of Philosophy, Henrik Ibsen's plays (A Doll's House in eleven languages), and the Universal Declaration of Human Rights. The basic design feature is the chunking of texts into sentence-like units that may be displayed in parallel. The result is reminiscent of the great polyglot Bibles of the sixteenth and seventeenth centuries. A similar technique of sentence-level chunking is employed in the Lili Elbe Digital Archive to coordinate Danish, German, and English versions of a modernist transgender narrative (CAUGHIE et al. n.d.). Meanwhile, researchers at the University of Chicago are developing a database structure that may serve as a universal framework for digital textual studies. Textual variance, the physicality of text-bearing artifacts, and multilingual transmission histories are all built in at the ground level. The project is termed Critical Editions for Digital Analysis and Research (CEDAR) and its directors have given a clear account of their purpose and thinking (SCHLOen and Schloen 2019, 2014). Each of these projects gives some sense of how digital editions may trace the "life of works" across languages. The CEDAR team has comprehensively re-thought the ways that humanists use computers to preserve, curate, analyze, and display text.

Eggert writes in conclusion that his "new literary studies", grounded in the disciplines of textual studies, bibliography, and book history, "is the most obvious way forward if we are to unlock the history of meanings, including, importantly, our own" $(2019,178)$. To unlock the history of meanings, including our own: this is the disciplinary purpose claimed for philology by Sheldon Pollock in a programmatic essay that, like Eggert's book, attempts to hold in balance the planes of literary genesis, transmission, and our own experience (Pollock 2014). Why philology? The reason is not just that philology, conceived as the study of languages, expands the horizon of our possible literary experience. As the study of literary language, philology is founded in a presumption that the language of literature is other, not our own. Thence springs a dialectic of self and other that extends from matters of sense and usage up into the domains of imaginative experience and selfunderstanding. To textual studies, bibliography, and book history - Eggert's trio of foundational disciplines — one must add philology, the study of the linguistic material of literature. ${ }^{1}$

Loyola University Chicago

1. I am grateful to Laura Gawlinski for conversation about ancient Greek sculpture and to Elizaveta Strakhov for comments that improved this essay. My reference to the CEDAR project is owed to Paul himself, who made the introduction. 


\section{Works Cited}

Beecroft, Alexander. 2015. An Ecology of World Literature: From Antiquity to the Present Day. New York: Verso.

Bra arvig, Jens, and Asgeir Nesøen. 2007-2015. Bibliotheca Polyglotta. University of Oslo, Norwegian Institute of Palaeography and Historical Philology. @ https:// www2.hf.uio.no/polyglotta/index.php.

Caughie, Pamela L., Sabine Meyer, Rebecca J. Parker, and Nikolaus Wasmoen, eds. n.d. Lili Elbe Digital Archive. @ http://lilielbe.org/.

Donaldson, E. Talbot. 1972. "The Psychology of Editors of Middle English Texts". In Speaking of Chaucer, 102-18. New York: Norton.

Duggan, Hoyt N. 1993. "The Electronic Piers Plowman B: A New Diplomatic-Critical Edition”. Æstel 1: 55-75.

Eggert, Paul. 2009. Securing the Past: Conservation in Art, Architecture and Literature. Cambridge: Cambridge University Press.

- 2019. The Work and the Reader in Literary Studies: Scholarly Editing and Book History. Cambridge: Cambridge University Press.

Gabler, Hans Walter. 1994. "Textual Criticism”. In The Johns Hopkins Guide to Literary Theory and Criticism, edited by Michael Groden and Martin Kreiswirth, 708-14. Baltimore: The Johns Hopkins University Press.

2010. "Thoughts on Scholarly Editing". Ecdotica 7: 105-27.

2012. "Beyond Author-Centricity in Scholarly Editing". Journal of Early Modern Studies 1 (1): 15-35.

Hallett, C[hristopher] H. 1995. "Kopienkritik and the Works of Polykleitos". In Polykleitos, the Doryphoros, and Tradition, edited by Warren G. Moon, 121-60. Madison: University of Wisconsin Press.

Hanna, Ralph. 1987. "Problems of 'Best Text' Editing and the Hengwrt Manuscript of The Canterbury Tales". In Manuscripts and Texts: Editorial Problems in Later Middle English Literature, edited by Derek Pearsall, 87-94. Cambridge: Brewer.

- 1988. "A la Recherche du temps bien perdu: The Text of The Awntyrs off Arthure". TEXT: Transactions of the Society for Textual Scholarship 4: 189-205.

1996. Pursuing History: Middle English Manuscripts and Their Texts. Figurae: Reading Medieval Culture. Stanford: Stanford University Press.

2000. "The Application of Thought to Textual Criticism in All Modes with Apologies to A. E. Housman”. Studies in Bibliography 53: 163-72.

2013. Introducing English Medieval Book History: Manuscripts, Their Producers and Their Readers. Exeter Medieval Texts and Studies. Liverpool: Liverpool University Press.

2015. Editing Medieval Texts: An Introduction, Using Examplary Materials Derived from Richard Rolle, "Super Canticum" 4. Exeter Medieval Texts and Studies. Liverpool: Liverpool University Press.

2017. Patient Reading/Reading Patience: Oxford Essays on Medieval English Literature. Exeter Medieval Texts and Studies. Liverpool: Liverpool University Press. 
Marvin, Miranda. 1997. "Roman Sculptural Reproductions or Polykleitos: The Sequel". In Sculpture and Its Reproductions, edited by Anthony Hughes and Erich RAnfFT, 7-28. London: Reaktion Books.

2008. The Language of the Muses: The Dialogue Between Roman and Greek Sculpture. Los Angeles: Getty Publications.

Pollock, Sheldon. 2014. "Philology in Three Dimensions". Postmedieval: A Journal of Medieval Cultural Studies 5 (4): 398-413. @ https://doi.org/10.1057/pmed.2014.33.

Schloen, David, and Sandra Schloen. 2019. "Critical Editions for Digital Analysis and Research (CEDAR) - A Computational Platform for Building Online Critical Editions”. Accessed May 28, 2020. @ https://voices.uchicago.edu/cedar/.

2014. "Beyond Gutenberg: Transcending the Document Paradigm in Digital Humanities”. Digital Humanities Quarterly 8 (4).

Stewart, Andrew. 1990. Greek Sculpture: An Exploration. 2 vols. New Haven: Yale University Press.

Tanselle, G. Thomas. 1983. "Classical, Biblical, and Medieval Textual Criticism and Modern Editing”. Studies in Bibliography 36: 21-68. 